\title{
Two's company, three's a crowd: Fine-scale habitat partitioning by depth among four sympatric species of marine mesopredator
}

\author{
Nicolas E. Humphries ${ }^{*}$, Samantha J. Simpson ${ }^{\text {ab }}$, Victoria J. Wearmouth ${ }^{\text {a }}$, David W. Sims ${ }^{\text {abc }}$ \\ ${ }^{a}$ Marine Biological Association of the United Kingdom, The Laboratory, Citadel Hill, Plymouth PL1 \\ 2PB, UK \\ ${ }^{\mathrm{b}}$ Ocean and Earth Science, National Oceanography Centre Southampton, University of Southampton, \\ Waterfront \\ Campus, European Way, Southampton SO14 3ZH, UK \\ ${ }^{c}$ Centre for Biological Sciences, Building 85, University of Southampton, Highfield Campus, \\ Southampton SO17 1BJ, UK1 \\ *Corresponding author: E-mail: nicmph@mba.ac.uk
}

\begin{abstract}
A sympatric assemblage of morphologically similar predators is expected to exhibit fine-scale habitat segregation, or resource partitioning, to reduce the effects of direct competition. This principle has been well studied for predators in terrestrial ecosystems.

In the marine environment, how sympatric species of large predators spatially segregate at the finescale is poorly understood because detailed movement and behavioural data is often not available across multiple species within the same timeframe. How co-occurring congeneric predators separate spatially is even less well understood.

Medium sized species of skates (Genus Raja) co-occur in temperate habitats of the north-east Atlantic Ocean, share similar morphologies and have distributional ranges that overlap significantly in the western English Channel ecosystem. Here, detailed depth time series retrieved from 89 electronic data storage tags attached to four species of skate were analysed to determine preferred depth ranges.

The four species were found to segregate spatially into two groups, with one group having a significantly shallower core annual depth range than the other. To our knowledge fine-scale segregation by depth has not been observed previously. Interestingly the members of each species group appeared complementary, each group comprising species having different dietary preferences and with a larger and smaller body size.
\end{abstract}




\section{Habitat partitioning in marine predators}

An understanding of how core depth ranges differ and how these species utilise vertical habitat has potential to predict geographic ranges around the coast with important implications for how these species interact with fisheries and Marine Protected Areas.

\section{Key-words}

Segregation, Resources, Marine, Raja, Ray, Skate, Niche

\section{Introduction}

How animals with similar resource requirements avoid direct competition is an important ecological question, which, at least in the terrestrial realm, has received much attention. Concepts such as niche partitioning have been developed to further our understanding of the morphological and behavioural adaptations seen in coexisting animals with competitive overlap, such as African feline predators. For example lions, cheetahs, leopards, caracals and servals coexisting in and around the African savannah exhibit a complex array of adaptations such as differing prey specialities, morphologies and life history traits, resulting in resource partitioning and, consequently, reduced direct competition (Hayward \& Kerley 2008, Owen-Smith \& Mills 2008). Niche partitioning can also involve behavioural adaptations, for example differing thermoregulatory behaviour in tiger beetles (Brosius \& Higley 2013) or activity patterns in lizards (Vitt \& Zani 1996). In sympatric assemblages of birds, niche partitioning is evident in the location of nesting sites where clear habitat preferences have been observed with elevation, aspect and slope position being important habitat features (Dellinger et al. 2007), in addition to tree species and ground cover (Martin 1998).

In marine ecosystems and for elasmobranchs in particular, several drivers of resource partitioning have been identified. Where spatial overlap occurs, for example in reef sharks or stingrays, temporal or dietary differences have been found that allow coexistence (Cartamil et al. 2003, Speed et al. 2012). In an assemblage of reef sharks, while there was considerable overlap in the areas occupied, differences were found in the times of peak abundance between the species (Speed et al. 2011). It was found that Carcharhius melanopterus abundance peaked between 13:0 and 14:00 while $C$. amblyrhnchos abundance peaked earlier, at 10:00, suggesting a temporal partitioning of resources and diel movement patterns. In an Australian assemblage of stingrays resource partitioning was found to comprise a complex of habitat preferences and dietary differences with ontogenetic changes in diet resulting in narrowing diet breadth and reduced dietary overlap with increasing age (Platell et al. 1998). Stomach content and stable isotope studies have found diet to be an important component of resource partitioning (Speed et al. 2012), with trophic structure often based on teleost/crustacean divisions (Espinoza et al. 2015, Hussey et al. 2015b). Where dietary overlap has been identified, for example in pelagic sharks in the Hawaiian Islands, niche partitioning has been achieved through 


\section{Habitat partitioning in marine predators}

spatial (geographic) segregation (Papastamatiou et al. 2006). Raja spp. generally have broad diets (Farias et al. 2006, Šantić et al. 2012) and there can be significant dietary overlap (Valls et al. 2011), despite individual specialisations. For Raja spp. therefore, spatial segregation, or habitat preferences, could be an important driver of resource partitioning.

Habitat partitioning is perhaps one of the clearer indications of niche separation, being easier to observe than prey preferences or behavioural adaptations, especially in cryptic ecosystems such as marine or freshwater habitats. Indeed habitat preferences have been observed in many different taxa in aquatic ecosystems, for example, freshwater fish in chalk streams (Prenda et al. 1997), in marine fish such as gurnards (Lopez-Lopez et al. 2011), pipefish (Malavasi et al. 2007) and sharks (Ceccarelli et al. 2014, Legare et al. 2015), and in copepods (Mackas et al. 1993).

In the marine environment habitat preferences, for example for particular substrates, temperatures or depths, are fundamental drivers of species distributions, migrations and fine-scale movements (Speed et al. 2010, Gouraguine et al. 2011, Queiroz et al. 2016). Consequently, an understanding of habitat preferences is essential when considering conservation strategies (Kaiser 2005, Speed et al. 2010, Queiroz et al. 2016). This is particularly relevant to marine ecosystems where many species have been overexploited and regulations to control or limit harvesting have resulted in reduction measures such as Marine Protected Areas (MPAs) that exclude or partially exclude fisheries (McCauley et al. 2015). However, in contrast to terrestrial ecosystems, fine-scale information concerning the movements and habitat preferences of multiple species of marine predators within the same geographical region is generally lacking (Block et al. 2011), making reliable conservation planning difficult, despite the pressing need to reduce overexploitation (Thurstan et al. 2010).

Historically, commercial fishing or research trawl survey data have been used to examine large-scale patterns in species distributions, including differences in depth range occupation among sympatric species (Gouraguine et al. 2011). However, it is not possible with these coarse sampling approaches to examine fine-scale differences in the habitats occupied by many individuals of multiple species continuously through time. Recent advances in electronic data logging devices (tags) have opened a window on the complex behaviour of marine predators, providing insights into foraging and migratory patterns (both horizontal and vertical) of commercially important species including cod, skates, tunas, sharks and billfish (Hunter et al. 2006, Hobson et al. 2007, Sims et al. 2008, Humphries et al. 2010, Block et al. 2011, Hussey et al. 2015a). Tracking the movements of individual fish of sympatric species offers a way to investigate habitat partitioning. For example, the large-scale movements of three, wide-ranging species of pelagic shark from the family Lamnidae (salmon shark Lamna ditropis; shortfin mako Isurus oxyrinchus; white shark Carcharodon carcharias) were tracked simultaneously in the Eastern Pacific Ocean (Block et al. 2011). Spatial separation was demonstrated between the three species over a large scale, encompassing $40^{\circ}$ of latitude and more than $30^{\circ}$ of 


\section{Habitat partitioning in marine predators}

longitude, consistent with their active behaviours and wide-ranging distributions, with the species essentially exhibiting latitudinal zonation rather than fine-scale niche separation. While fine-scale habitat partitioning might be difficult to identify in active, wide ranging pelagic species, it might be found in the study of less active, benthic mesopredators, such as skates.

Skates are marine mesopredators strongly adapted for the benthic environment with a worldwide distribution in all oceans. These elasmobranchs differ from their benthic teleost counterparts in this local assemblage, such as plaice (Pleuronectes platessa) or turbot (Psetta maxima), principally by being dorso-ventrally, rather than laterally, flattened and by having ventrally positioned mouths. Unlike most teleosts, including plaice, skates are $k$-selected species with a late age at maturity and low fecundity, making them vulnerable to overexploitation (Field et al. 2009, Dulvy et al. 2014). They also lack a planktonic life history stage, resulting in reduced dispersal and low re-colonisation potential compared to teleost benthic predators (van der Molen et al. 2007, Frisk et al. 2014). Studies using research trawl data have found depth to be an important factor in the segregation of the four elasmobranch species studied here (Gouraguine et al. 2011) with complex patterns of spatial segregation and apparent differential habitat preferences also being identified in the Eastern North Pacific (Bizzarro et al. 2014). The aforementioned study found depth to be the primary axis of segregation although it was suggested that the driver could be temperature, which was strongly correlated with depth. Interestingly, where species overlapped, the coexisting species were found to differ in size, which suggests some further level of niche partitioning. Segregation, or zonation, by depth has also been found in the South African assemblage of skates (Compagno et al. 1991, Compagno \& Ebert 2007) and would therefore appear to be a common occurrence among skates over the large scales at which these studies were performed. However, all these studies are large (geographic) scale and have investigated separation at a species level into different populations with different habitat preferences. Less is known about fine-scale habitat segregation in sympatric assemblages of skates where the species co-exist over a relatively small geographical extent. This significant gap in our understanding is unsurprising given the cryptic nature of benthic predators that makes direct observation impractical and where the majority of data concerning habits and diet are derived from fisheries or trawl surveys (Bizzarro et al. 2014). Data from both fisheries and trawl surveys are inevitably sparse and the distribution of fishing effort can result in a significant bias (Bolle et al. 2005), making any conclusions regarding ecological concepts such as habitat preferences or resource partitioning somewhat speculative. Further, temperate marine benthic environments very rarely benefit from in situ observations that can prove so useful in elucidating behaviour and habitat preferences (Eggleston et al. 2013).

There are four species of skate that are commonly found in southern UK waters in the western English Channel (WEC) ecosystem: Raja brachyura (blonde ray; LaFont, 1871), R. clavata (thornback ray; 
Linnaeus, 1758), R. microocellata (small-eyed ray; Montagu, 1818) and R. montagui (spotted ray; Fowler, 1910). These species have been common and widespread since the last glacial maximum some 20000 years ago (Chevolot et al. 2006b) with distributional ranges that overlap significantly in the WEC (Ellis et al. 2005b), although abundance has declined since the 1950s as a result of fishing pressure (Chevolot et al. 2006a, Genner et al. 2010). In order to reduce direct competition, it might be expected that these four sympatric species would exhibit significant differences in morphology and life history (Hardin 1960). However, this closely related congeneric group (McEachran \& Dunn 1998, Ebert \& Compagno 2007) show considerable morphological similarity and until recently were simply classified as 'skates and rays' in fisheries landings data (Dulvy et al. 2000). The most obvious difference between the four species is an inter-species maximum recorded size range of around 1.5 times between the smallest ( $R$. montagui) and the largest species ( $R$. brachyura). Further, their dietary requirements are also broadly similar, being generalist predators of crustaceans and fish with considerable overlap, especially between juvenile individuals (Ellis et al. 1996). Consequently, at present, how resources are partitioned in these species to enable their apparent close coexistence is not known.

To address this knowledge gap, we investigated the fine-scale habitat use of the four sympatric skates with tracking data collected simultaneously throughout the study area. This study analyses datasets for four species of skate ( $R$. brachyura, $R$. clavata, $R$. microocellata, $R$. montagui), from 179 tags deployed from July 2007 to May 2013 off Plymouth, UK. The long-term depth time-series were analysed to determine (i) whether core depth preferences can be identified in each species; (ii) to determine whether preferred depths differ sufficiently to indicate habitat segregation, and (iii) how preferences change over seasonal time-scales. To identify core depth preferences the study used weekly mean depths for each species. To determine differences in depth preferences the overlap in weekly time at depth occupancy between the species and how this overlap changes on seasonal timescales was examined, providing a first step in understanding the complex behaviours underlying coexistence and niche partitioning.

\section{Materials and methods}

\section{Tags and tagging}

Adult or sub-adult fish were captured during routine research survey trawls in inshore waters of the WEC between Whitsand Bay (50.34 N, 4.28 W) and Bigbury Bay (50.26 N, 3.89 W). Fish were tagged using data storage tags (DST), either CTL G5 (www.cefastechnology.co.uk, UK), or Star Oddi (star-oddi.com; Star-Oddi, Iceland). Standard G5 DSTs were $31 \mathrm{~mm}$ long by $8 \mathrm{~mm}$ diameter and weighed $1 \mathrm{~g}$ in water, whereas long-life G5 DSTs measured $35.5 \mathrm{~mm}$ long x $11.5 \mathrm{~mm}$ diameter and weighed $2.1 \mathrm{~g}$ in water. Star Oddi DSTs were $39.4 \mathrm{~mm}$ by $13 \mathrm{~mm}$ and weighed $5 \mathrm{~g}$ in water. DSTs 


\section{Habitat partitioning in marine predators}

monitor temperature from 2 to $34{ }^{\circ} \mathrm{C}$ (accuracy $0.1{ }^{\circ} \mathrm{C}$, resolution $0.03{ }^{\circ} \mathrm{C}$ ) and pressure to a depth of $100 \mathrm{~m}$ or $200 \mathrm{~m}$ (accuracy 1\%, resolution $0.04 \%$ ) depending on tag type (see supplementary table $\mathrm{S} 1$ ). All DSTs were programmed to record depth at $20 \mathrm{~s}, 30 \mathrm{~s}$ or 1 min intervals. All tags also recorded temperature every $10 \mathrm{~min}$. DSTs were attached to skates via Peterson disc tagging using the methods described by Wearmouth \& Sims (2009). Briefly, tags were mounted in a stainless steel wire cradle with a long, pointed stainless steel wire attachment. This wire was passed through a Peterson disc and then passed dorso-ventrally through the pectoral fin, taking care to avoid the abdominal cavity. A second Peterson disc was then placed onto the length of wire on the opposite (ventral) side of the animal before securing the attachment by turning a series of rounds into the length of wire remaining. Tagging was typically accomplished in less than 2 minutes, including the measurement of total length and body width. Animals were immediately transferred to on board aquaria with fresh running sea water for observation prior to release within the hour. All tagging procedures were approved by the Marine Biological Association Animal Welfare and Ethical Review Body (AWERB) and licensed by the UK Home Office under the Animals (Scientific Procedures) Act 1986. DSTs were returned through the commercial net and trawl fisheries operating in the WEC with a reward of $£ 50$ given for return of the DST and the fish, or for information about the size of the fish and where it was captured.

\section{Data analysis}

Several approaches were taken to determine core depth occupancy, separation and the degree of overlap in vertical habitat use. To determine core depth preferences and how depth usage changed over time at seasonal timescales, weekly mean depths were computed from all pooled individuals and plotted for each species. To examine depth preferences at a finer temporal scale, diel depth profiles were computed whereby the mean depth in hourly depth bins was computed for all individuals in each species. Additionally, to investigate possible drivers of habitat preferences, weekly mean temperatures were also computed from the time-series data.

To investigate overall depth occupancy and the extent of the vertical habitat exploited, time at depth plots were built by computing percentage time at depth for all individuals. The depth time-series data returned by the tags are complex and represent movements encompassing a rich behavioural repertoire with considerable variability both between and within species and individuals. To reveal this fine-scale detail the datasets were used to populate time at depth (TAD) matrices, constructed with $4 \mathrm{~m}$ depth bins (rows) and weekly time bins (columns), whereby all the data for each species could be accumulated into a single matrix. The matrices were constructed with a maximum depth of $80 \mathrm{~m}$ which was sufficient to encompass the recorded depths and consequently a $4 \mathrm{~m}$ depth bin was chosen as this provided 20 depth bins. 


\section{Habitat partitioning in marine predators}

To reduce bias introduced by the datasets having differing durations and extents, computed TAD values were normalised by dividing by the number of datasets contributing to each grid cell to give a mean TAD value. The resulting TAD matrices were initially compared visually by producing contour plots. To further investigate shared depth occupancy between pairs of matrices, a shared TAD occupancy matrix was computed with values for each grid cell calculated using:

$$
S= \begin{cases}0 & \text { if } p 1=0 \text { or } p 2=0 \\ (1+p 1) *(1+p 2) & \text { otherwise }\end{cases}
$$

Where $p 1$ is the occupancy value from one species and $p 2$ the value of the other. This equation is used as the normalised TAD values can be $<1.0$. To provide a numerical comparison of the matrices an overlap coefficient was computed using the following equation (Horn 1966, Rijnsdorp et al. 1998):

$$
O=2 \sum_{j}\left(P_{a j} \cdot P_{b j}\right) /\left(\sum_{j} P_{a j}^{2}+\sum_{j} P_{b j}^{2}\right)
$$

Where $P_{a j}$ represents the TAD value for species $a$ in grid cell $j$ and $P_{b j}$ the corresponding value for species $b$. Using this equation it is possible to compute an overlap coefficient for either the entire matrix, or for sub-sets of grid cells, such as all cells in each column to provide a week by week coefficient, or for all grid cells in each row to give overlap coefficients for each depth range. These coefficients range in value from 0.0 (no overlap) to 1.0 (matching occupancy) and provide a straightforward way in which to determine similarity between TAD matrices constructed for different species. To determine the statistical significance of the overlap coefficients a null model was used with a Monte-Carlo approach in a two-step process. First, for each pair of matrices (M1 \& M2) being analysed, a null value was computed using a randomised M1 matrix and the original M2 matrix, with this being repeated 5000 times. For each iteration a count was maintained of the number of the times the randomised value $\left(O C_{r}\right)$ was $<$ the observed value $\left(O C_{o}\right)$. The process was then repeated a further 5000 times with instead M2 being randomised and M1 being the original, to give a total number of randomisations $(\mathrm{R})$ of 10000 . A mean value $\left(O C_{r m}\right)$ was calculated for all randomisations.

The randomisation process was a conservative approach based on the RA4 option in EcoSim (Gotelli \& Ellison 2013), whereby each non-zero value was swapped with a randomly selected non-zero value. This approach preserves the overall time at depth structure but modifies the distribution of 'hot' and 'cold' spots. Examples of randomised matrices are given in Supplementary Methods, Figures S5-S6.

Where the mean randomised $\left(O C_{r m}\right)$ value was greater than the observed $\left(O C_{o}\right)$ value this suggested that the observed overlap was less than expected by chance and therefore the count of $\left(O C_{r}<O C_{o}\right) / R$ provides a $p$-value. Conversely, where $O C_{r m}<O C_{o}$ this suggests that the observed overlap is greater than expected by chance and then $10000-\left(O C_{r}>O C_{o}\right) / R$ provides the $p$-value. For example, if the 


\section{Habitat partitioning in marine predators}

observed overlap coefficient was 0.26 , the mean randomised coefficient was 0.32 and 9793 of the randomisations produced a coefficient greater than observed, then the observed overlap can be said to be significantly less than expected by chance, with a $p$-value of 10000-9793 / $10000=0.0207$.

The long time scale of the tagging activities/deployments and the short length of some of the datasets (range, $2-419$ days; mean $=140 \mathrm{~d} \pm 116$ S.D., $\mathrm{n}=89$ ) inevitably resulted in some gaps between individuals across seasons and years. To account for the gaps, in all the analyses we overlaid all data to a single year, making the assumption that on an annual scale individual species within the study area likely exhibit similar behaviours and activities between years.

To determine the statistical significance of the separation by depth and to account more fully for individual variation, a mixed effects linear model was run using the R lmer function (Winter 2013, Bates et al. 2015, R Development Core Team 2015). The model used was Mean Depth $\sim$ Species + Week $+(1 \mid$ Individual) with a null model of Mean Depth $\sim$ Week $+(1 \mid$ Individual). The models were run using weekly mean depth data from all individuals and were compared using ANOVA to determine whether Species had a significant effect.

\section{Results}

\section{Tag returns and available datasets}

Of the 179 tags deployed, 92 (51.4\%) were returned with 89 having useable data with a total of $35 \mathrm{x}$ $10^{6}$ data points totalling 12,585 days. A summary of the datasets available is given in Table 1, further details are given in Supplementary Information Table S1. Recapture locations were recorded for 64 tags giving a mean displacement of $12.09 \mathrm{~km} \pm 13.26$ S.D. (range, $0.33-63.96 ; n=64$ ). Median displacements for each species are given in Supplementary Information Table S2. For 59 animals (92\%) the displacement was $<30 \mathrm{~km}$ suggesting that these animals tended to remain in the area (Figure 1) in agreement with previous tagging studies (Hunter et al. 2005a, Chevolot et al. 2006a). No correlation was found between days at liberty and displacement (Pearson Product Moment Correlation $=0.0528, \mathrm{p}=0.678, n=64)$ indicating that the skates were not simply in transit through the area, but instead represent part of a more localised assemblage. Because we do not have geographic locations, other than the release and recapture points, it is not possible to confirm whether the animals are permanent residents or are simply exhibiting site fidelity. However, if animals were migrating away then returning to the site after significant periods away, then it would be more likely for captures to have occurred further afield. Consequently, although site fidelity cannot be ruled out, residency, at least for the animals for which tags were returned, seems more likely. The animals in the study can therefore be considered to be within the same spatial frame of reference, with this level of residency being likely in other locations around coastal areas. 
Although the differences in length and body width between species of the tagged animals were found to be significant (Kruskal-Wallis ANOVA on Ranks, $p=0.031$ and $p=0.034$ respectively), with $R$. clavata being slightly longer and $R$. brachyura slightly wider than the other three species (see Supplementary Information Table S3), there was in fact considerable overlap (Supplementary Information Figure S1) and the differences were very small. The tagged animals also had very similar masses, and while $R$. brachyura and $R$. clavata were slightly heavier, this was not found to be significant (Kruskal-Wallis ANOVA on Ranks, $p=0.16$, Supplementary Information Figure S1). Consequently, for the animals tagged in this study, there was no support for the general assumption that this sample of individuals would exhibit size driven segregation. Within species, size and weight ranges were greatest for $R$. clavata and smallest for $R$. montagui, with the ranges for $R$. clavata exceeding the range across species. These ranges are likely due to the larger sample size for this species. Some evidence for depth segregation by size might therefore be expected within $R$. clavata.

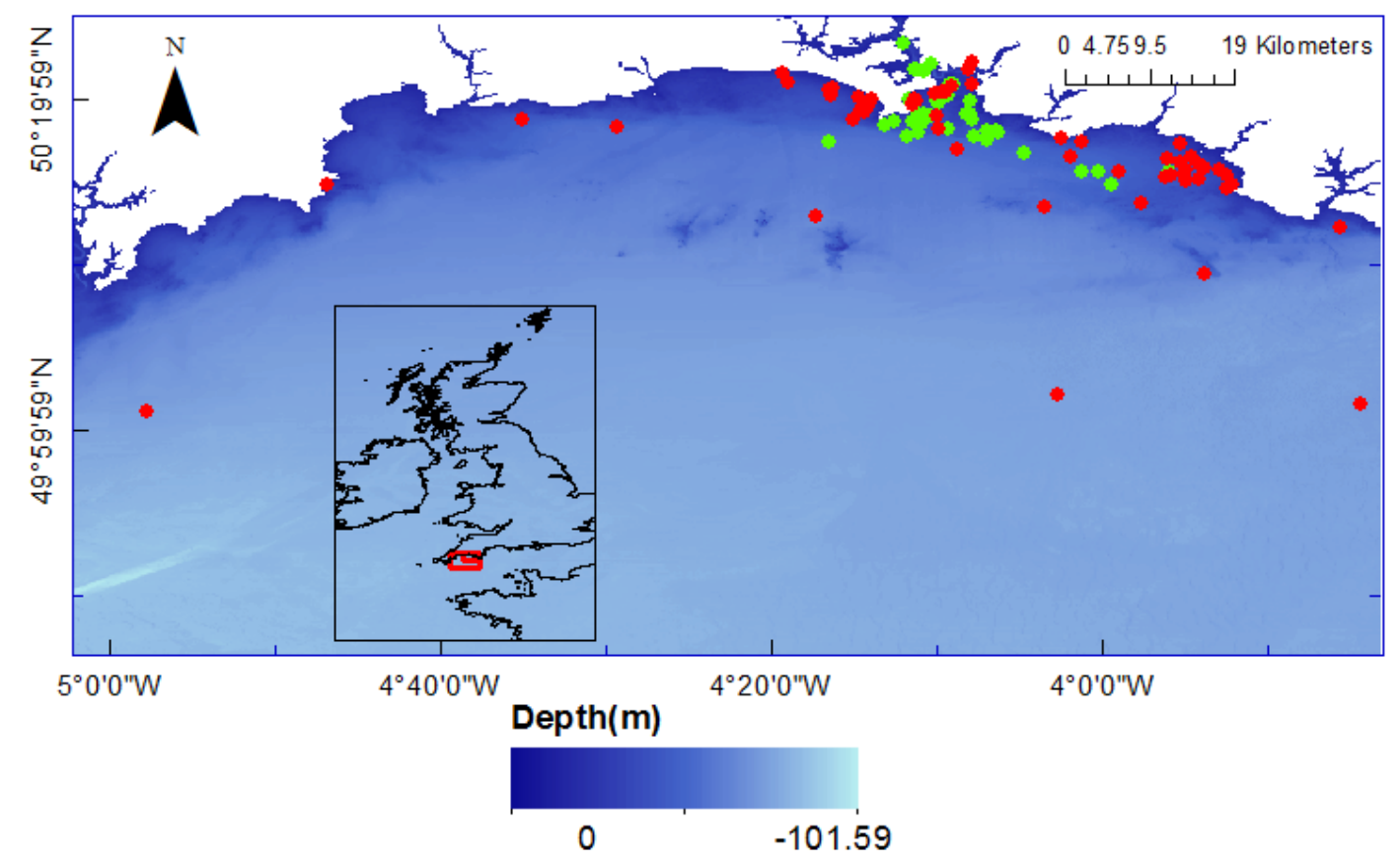

Figure 1: Tag release and recapture locations

Release locations shown in green, recapture locations in red. The majority of animals for which tags were returned remained close to the release location. Inset shows the study area in relation to the UK. 
Habitat partitioning in marine predators

Table 1: Datasets available for study (IUCN status NT: Near Threatened; LC: Least concern)

\begin{tabular}{lcccc}
\hline Species & Days of data & No of data points & No of individuals & IUCN status \\
\hline R. brachyura & 1,240 & $4,331,839$ & 12 & NT \\
R. clavata & 5,949 & $15,096,439$ & 43 & NT \\
R. microocellata & 3,501 & $11,084,059$ & 24 & NT \\
R. montagui & 1,895 & $4,927,843$ & 10 & LC \\
\hline Total & 12,585 & $35,440,180$ & 89 & \\
\hline
\end{tabular}

\section{Mean depth profiles}

The time depth profiles (Figure 2) show strong similarities with $R$. clavata and R. microocellata have very similar profiles, with peak depth occupancy around $10 \mathrm{~m}$. $R$. brachyura and $R$. montagui are also similar, both being much deeper than the other two, with $R$. brachyura having a mean depth occupancy of around $35 \mathrm{~m}$ and $R$. montagui around $45 \mathrm{~m}$. Although the preferred depth for $R$. microocellata is relatively shallow, this species exhibits a slightly greater range of depth use than either $R$. clavata or $R$. montagui. Differences between the median values for the two groups were significant ( $p<0.001$, Kruskal-Wallis One Way Analysis of Variance on Ranks).

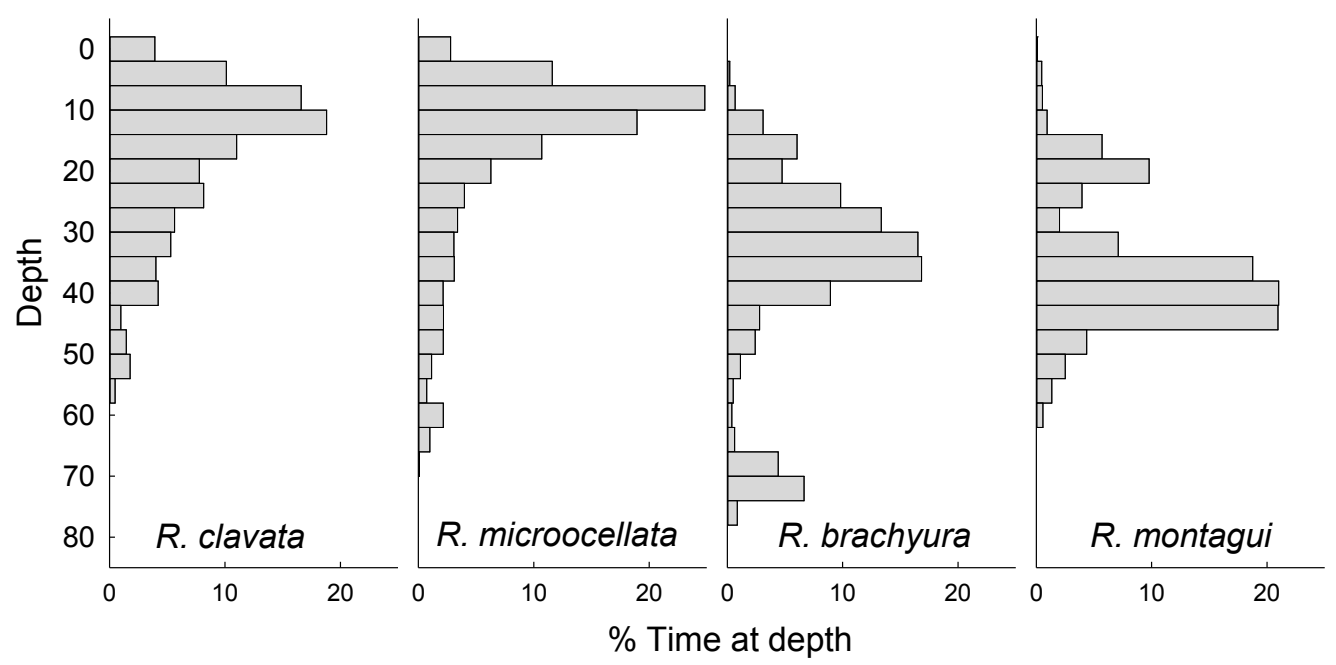

Figure 2: Time at depth profiles

Similarities between $R$. clavata and $R$. microocellata and between $R$. brachyura and $R$. montagui are clear in the time at depth profiles. For $R$. brachyura $n=12 ; R$. clavata $n=43 ; R$. microocellata $n=24 ;$. montagui $n=10$. 


\section{Habitat partitioning in marine predators}

\section{Weekly mean depths}

A plot of weekly mean depths, computed from all time-series for each species showed clear separation into the same two groups as the time at depth profiles described above (Figure 3). As each group comprises a 'pair' of species we will, for convenience, henceforth refer to these groups as species pairs; however, we are not implying any other connection or relationship between the species in each pair. Seasonal patterns were also evident within species pairs; $R$. microocellata changed depth to occupy shallower waters than $R$. clavata during the summer and autumn then deeper water in winter and spring. Of these two species, $R$. microocellata exhibits the greater range of mean depth, in agreement with the depth profiles shown in Figure 2. A similar pattern is apparent between $R$. brachyura and $R$. montagui, with $R$. brachyura initially in deeper water until late April when it moves to shallower waters for most of the summer. From September to December R. brachyura and $R$. montagui shared similar depths and showed a similar movement to slightly shallower waters. Interestingly the overall mean depths (indicated by the horizontal dashed lines in Figure 3) are remarkably similar for each of the two pairs with clear separation between them: $R$. clavata and $R$. microocellata exhibited shallower occupancy, with mean depths of 18 and $17 \mathrm{~m}$, while $R$. brachyura and R. montagui occupied deeper depths with mean values of $36.4 \mathrm{~m}$ and $35.6 \mathrm{~m}$.

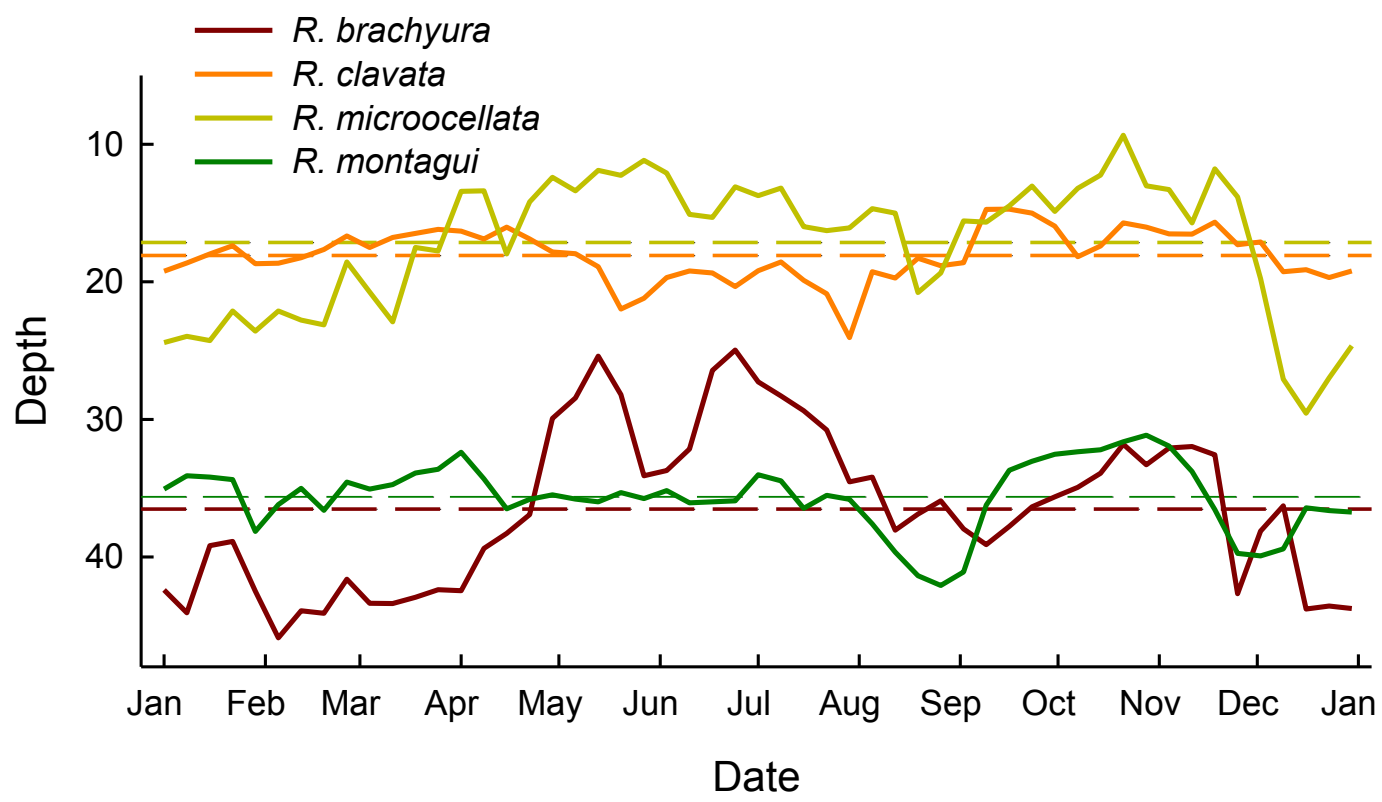

Figure 3: Weekly mean depths

Weekly mean depths computed from the depth time series. Dashed horizontal reference lines show the overall mean depth for each species indicating a very clear separation into two pairs. 


\section{Habitat partitioning in marine predators}

\section{Diel depth profiles}

Diel depth profiles computed using hourly depth bins for each species (Figure 4) show very little difference in depths occupied and correspond well to the mean depths computed from the weekly mean depths analysis. The error bars on this plot confirm the greater overlap between $R$. clavata and R. microocellata suggested in Figure 3

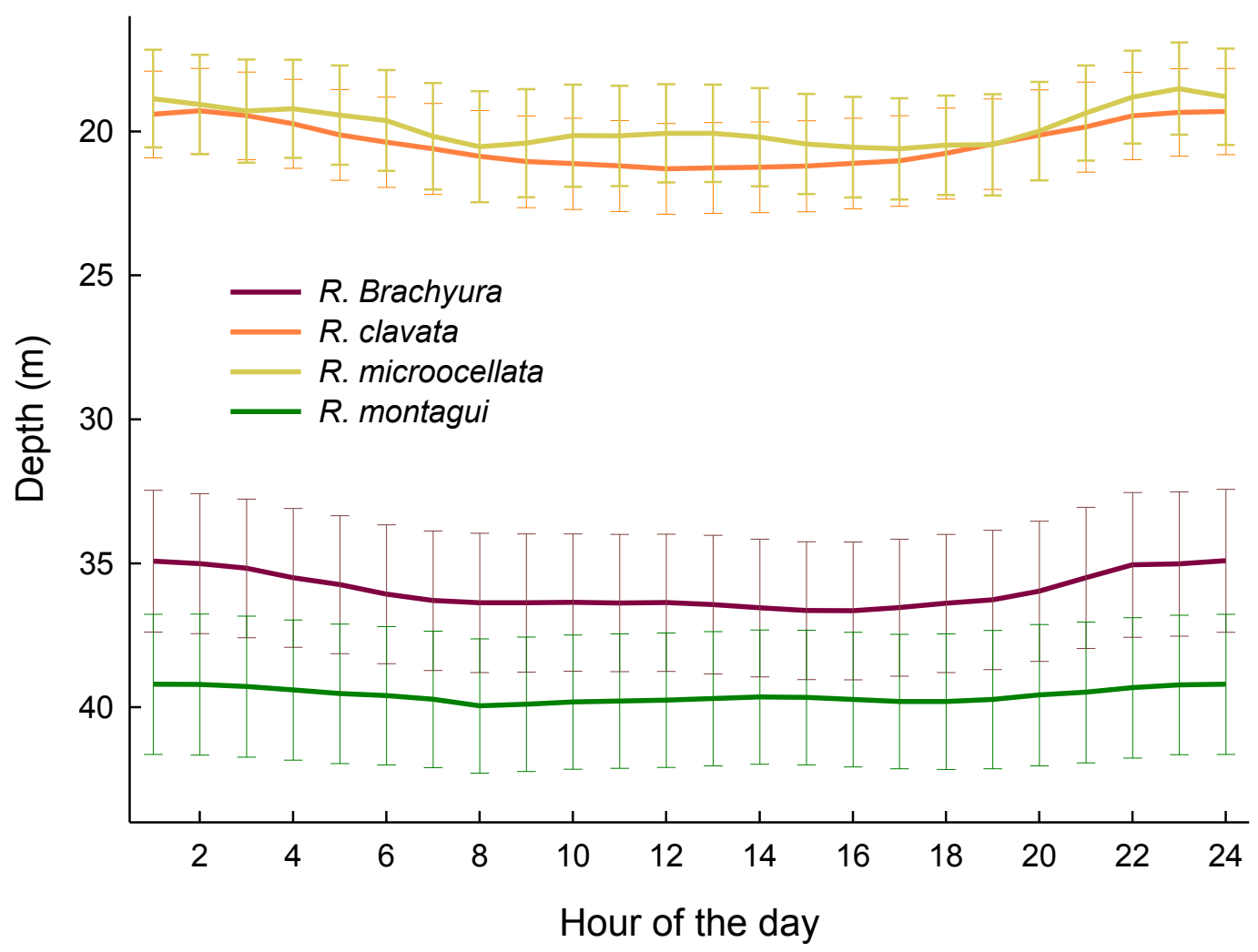

Figure 4: Diel depth profiles

Error bars show \pm std. error.

\section{Weekly mean temperatures}

In contrast to the differences found in weekly mean depths, no significant differences were found in weekly mean temperatures ( $p=0.484$ Kruskal-Wallis One Way Analysis of Variance on Ranks) in habitats occupied by skates, with temperatures for all species varying similarly with season (Figure 5). The only species where the temperature departed noticeably from the overall mean was $R$. brachyura during August to November. The largest temperature difference between any pair of species was 1.97 ${ }^{\circ} \mathrm{C}$, whereas the largest mean seasonal range was considerably greater at $7.25^{\circ} \mathrm{C}$. 


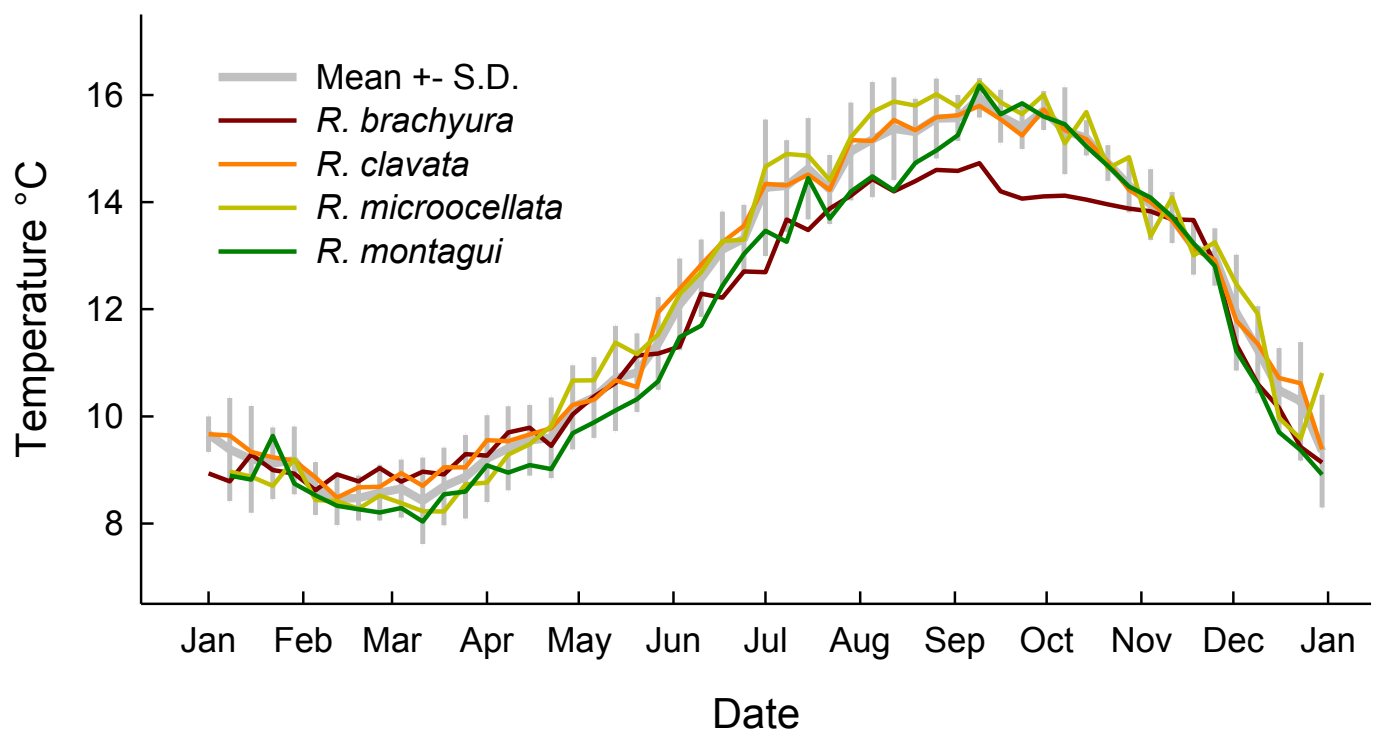

Figure 5: Weekly mean temperatures

Unlike mean depths, weekly mean temperatures do not differ significantly between species.

\section{Time at depth matrix analysis}

The contour plots produced from the time at depth (TAD) matrices illustrate the considerable range of depths occupied throughout the year (Figure 6). However, despite this wide range, in all cases a narrow band of highest depth occupancy was apparent, suggesting a preferred depth range for each species. Comparison of the TAD matrices confirms similarities in core depth occupancy identified in the weekly mean depth analysis that suggest that the species form two species pairs with respect to depth occupancy, with the bands of highest occupancy corresponding well to the mean values shown in Figure 3. The considerable range of depth use suggests a high degree of within species variability. Interestingly, despite having a consistently greater overall depth range, $R$. microocellata has the narrowest band of high occupancy, consistent with a stronger preference for the narrow depth range occupied.

The analysis shows clear hotspots of within-species shared occupancy for both $R$. clavata and $R$. microocellata, suggesting that in this data there are well defined preferred depth ranges for both species between 5 and $20 \mathrm{~m}$. There is some evidence for a seasonal shift in $R$. clavata, with deeper depths occupied during summer months; however, seasonal changes in core depth use are not evident in the other species. The deeper depths evident in the plot for $R$. brachyura resulted from the movements of just three individuals (A01846, A05950 and A05962). A01846 was in shallow water $(7-27 \mathrm{~m})$ from the start of the track in April, moved to deeper water $(78 \mathrm{~m})$ at the end of May and remained at that depth until the end of the 60 day track in mid-June. A05950 spent most of the 365day track at depths of around $45 \mathrm{~m}$ but descended to around $74 \mathrm{~m}$ in December, returning to $45 \mathrm{~m}$ by 


\section{Habitat partitioning in marine predators}

the end of May. A05962 spent the majority of the 260 day track at around $40 \mathrm{~m}$, but performed a brief excursion (18 days) to much deeper water (maximum depth $129 \mathrm{~m}$ ) at the end of July. Despite the variability between these individuals, the persistent core depth range is still clearly evident from the TAD plot.

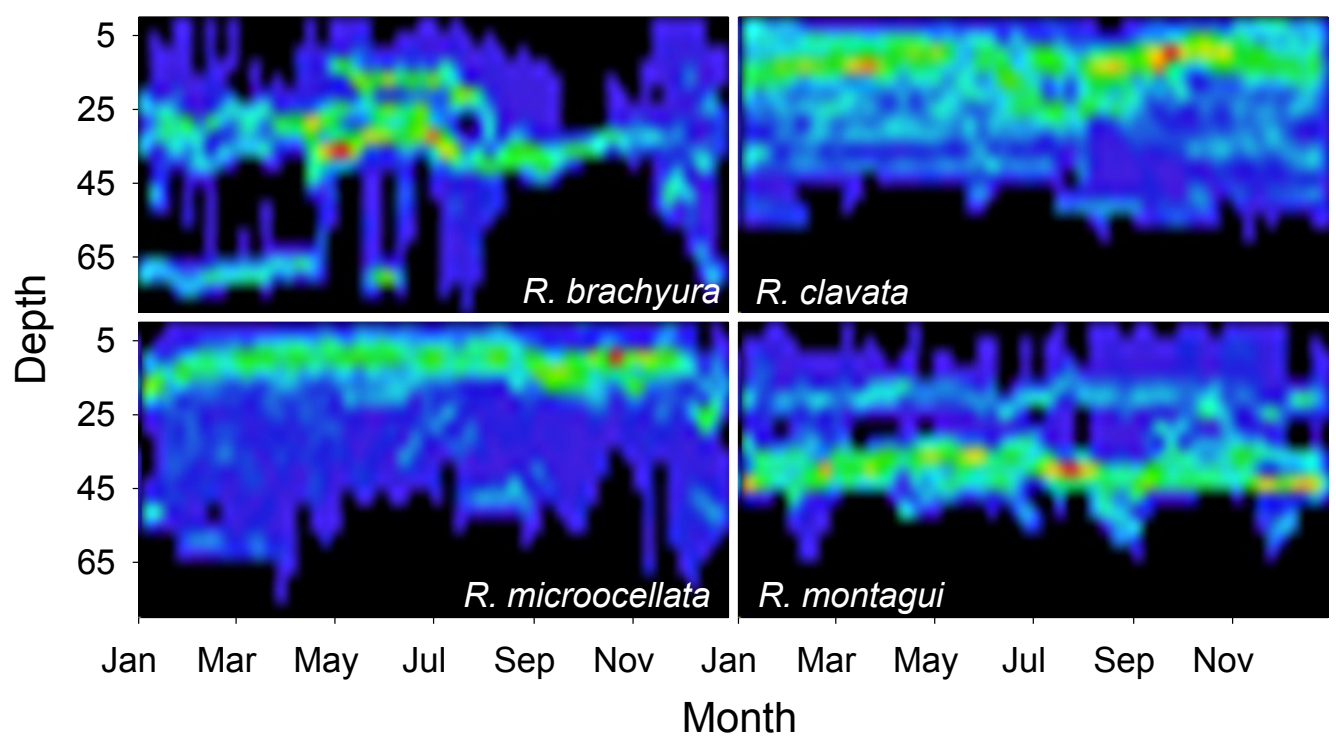

Figure 6: Time at depth plots for each of the four species

Warmer colours represent higher occupancy values. Similar core depth ranges are apparent for the (R. brachyura and R. montagui) and for (R. clavata and R. microocellata).

\section{Analysis of overlap coefficients}

Overlap coefficients calculated between all pairs of species using the TAD matrices described above further confirmed the putative grouping of the species into two pairs, with $R$. clavata and $R$. microocellata having a coefficient of 0.785 , representing more than $78 \%$ overlap in the TAD matrices $R$. brachyura and $R$. montagui have the next highest measure of overlap $(0.42)$ and $R$. microocellata and $R$. montagui had the lowest overlap values of 0.19 . Results of the statistical analysis are given in Table 2. In all cases the observed overlap, (or separation) was found to be statistically significant. 


\section{Habitat partitioning in marine predators}

Table 2: Statistical analysis of the overlap coefficient

$\downarrow$ indicates an overlap coefficient that is significantly less than expected by chance, $\uparrow$ indicates a value that is significantly greater

\begin{tabular}{l|l|c|c|c}
\hline & & R. clavata & R. microocellata & R. montagui \\
\hline \multirow{4}{*}{ R. brachyura } & Overlap coefficient & $\mathbf{0 . 2 6 1 1 9} \downarrow$ & $\mathbf{0 . 1 4 1 0 4} \downarrow$ & $\mathbf{0 . 4 1 7 0 1} \uparrow$ \\
& Mean randomised coefficient & 0.31868 & 0.26438 & 0.29828 \\
& $p$-value & 0.0016 & $<0.0001$ & 0.0001 \\
\hline \multirow{5}{*}{. clavata } & Overlap coefficient & & $\mathbf{0 . 7 8 5 4 6} \uparrow$ & $\mathbf{0 . 2 7 8 8 5} \downarrow$ \\
& Mean randomised coefficient & & 0.44463 & 0.43975 \\
& $p$-value & & $<0.0001$ & $<0.0001$ \\
\hline \multirow{3}{*}{ microocellata } & Overlap coefficient & & & $\mathbf{0 . 1 9 3 2 5} \downarrow$ \\
& Mean randomised coefficient & & & 0.35803 \\
& $p$-value & & & $<0.0001$ \\
\hline
\end{tabular}

The overlap coefficients for single columns (i.e. weeks) of the TAD matrices were computed for each pair of species to determine how the overlap in depth use changes throughout the year. These plots (Figure 7) show peaks when shared depth use between a pair of species is high; for example in Figure 7a, shared occupancy between $R$. brachyura and $R$. clavata peaks during summer months. Shared occupancy between $R$. brachyura and both $R$. clavata (Figure 7a) and R. microocellata (Figure $7 \mathrm{~b}$ ) is at a minimum during autumn, most likely reflecting the movement of $R$. brachyura into deeper water at this time. $R$. brachyura has, as expected, greater association with $R$. montagui (Figure $7 \mathrm{c}$ ) but with marked oscillatory peaks and troughs suggesting brief excursions into either deeper or shallower water by one or other of the pair. $R$. clavata clearly has a greater association with $R$. microocellata (Figure 7d) throughout the year, apart from in late summer and winter, although even then the association is greater than many of the other pairs at any time. As expected from the analysis described above, $R$. microocellata shows generally very little overlap with $R$. montagui (Figure $7 \mathrm{f}$ ). Seasonal trends were observed between $R$. brachyura and $R$. clavata (Figure 7a) with a clear peak in summer and a low point in autumn. A similar but weaker pattern is evident between $R$. brachyura and R. microocellata (Figure 7b). 


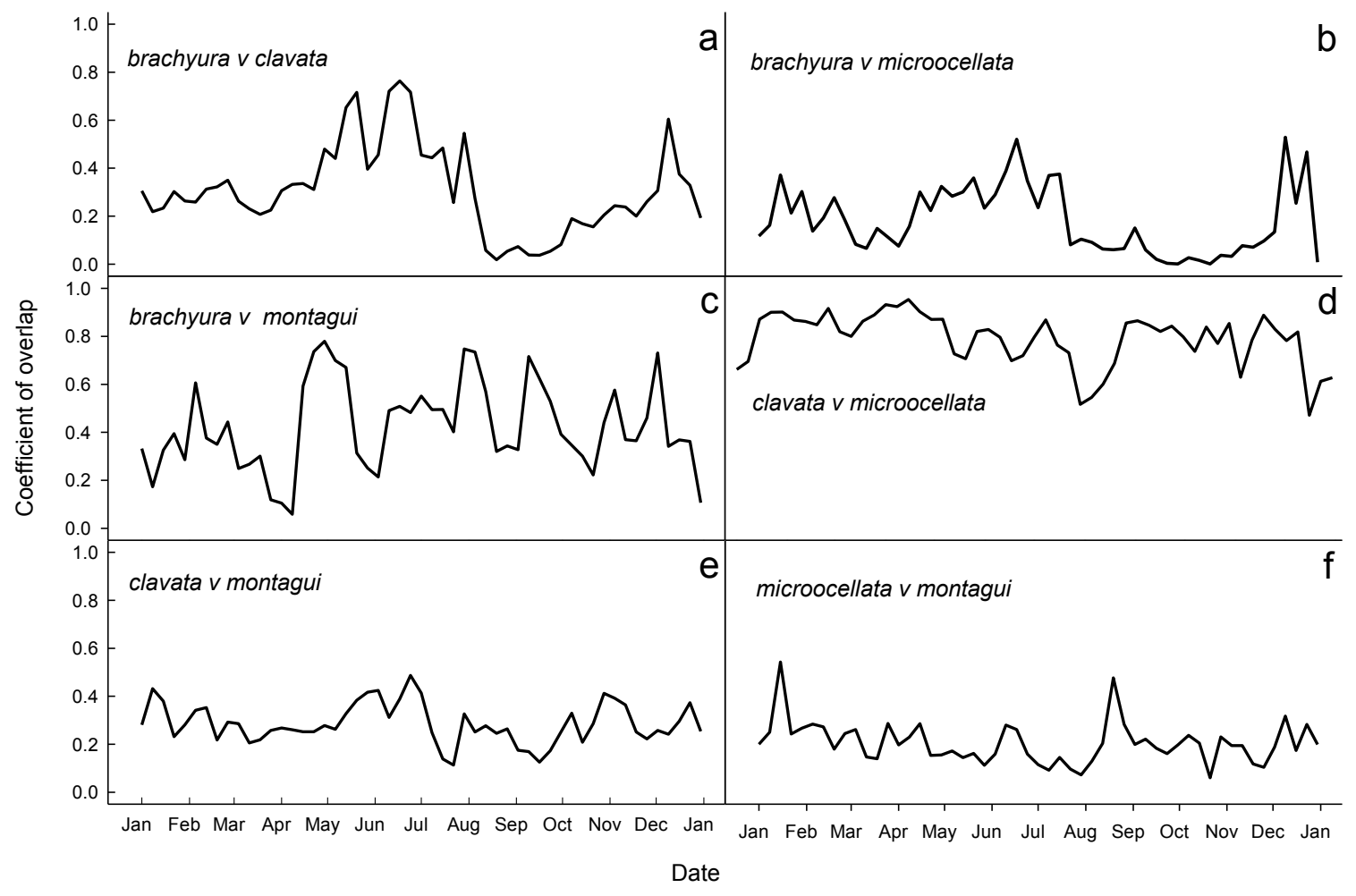

Figure 7 Weekly paired overlap coefficients

The panels show the paired, weekly overlap coefficients for the four species, i.e. the six possible pairings of the four species: a) $R$. brachyura $v R$. clavata; b) $R$. brachyura $v R$. microocellata; c) $R$. brachyura $v R$. montagui; d) $R$. clavata $v R$. microocellata; e) $R$. clavata $v R$. montagui; f) $R$. microocellata $v R$. montagui. While overlap is consistently low for $R$. clavata $v R$. montagui and $R$. microocellata $v R$. montagui, it is consistently high for $R$. clavata $v R$. microocellata. Spatial overlap for $R$. brachyura $v$ both $R$. clavata and R. montagui shows more complex behaviour with seasonal differences reflecting inshore and offshore movements.

\section{Using a mixed effect model to account for individual variation}

Linear modelling showed Species to have a significant effect on mean depth $(\chi 2(3)=47.755, p<0.001)$. The intercepts computed by the model, which are in relation to $R$. brachyura (the first species alphabetically), correspond well to the mean values computed in the weekly mean depth and diel depth profile analyses; mean depth was 15.57 and $16.24 \mathrm{~m}$ shallower for $R$. clavata and $R$. microocellata respectively and $3.8 \mathrm{~m}$ deeper for $R$. montagui. Week was seen to have a very small effect of only -0.046 , suggesting that there is no simple linear relationship between the week and the mean depth, as suggested previously by the seasonal changes in weekly mean depth. Full results from the output are given in the Supplementary Information. 


\section{Habitat partitioning in marine predators}

\section{Discussion}

Habitat use and resource partitioning is poorly understood in temperate, benthic elasmobranchs but is of considerable importance given the recent declines in some populations (Brander 1981, Casey \& Myers 1998) and especially given no global reduction in fishing pressure (Botsford et al. 1997, Worm \& Branch 2012). Indeed globally, the number of skates and rays landed has been higher than landings of sharks since about 1975, suggesting skate populations may be at greater risk of overexploitation than in prior decades (Field et al. 2009, Dulvy et al. 2014). Previous research into species distributions and habitat preferences in the Rajidae is sparse and has relied principally on trawl data, either from fisheries (Serra-Pereira et al. 2014), or from fishery independent surveys (Compagno et al. 1991, Dulvy et al. 2000, Hunter et al. 2005b, Hunter et al. 2006, Compagno \& Ebert 2007, Maravelias et al. 2012, Martin et al. 2012). Studies such as these are typically very large scale and lack information about fine scale movements and behaviours which can significantly affect species interactions and distributions (Hussey et al. 2015a). It is known, for example, that $R$. clavata in the Eastern English Channel perform spawning migrations to estuarine environments (Hunter et al. 2005b, Hunter et al. 2006), which differ from the habitat in which they are generally found. Ontogenetic differences in habitat use have also been identified in $R$. clavata with younger individuals occurring in shallower areas over fine sand or mud, while older individuals are more widely dispersed and inhabit deeper waters (Martin et al. 2012). However, a study by Ellis et al. (2011) showed that, around Jersey (Channel Islands, UK), R. clavata show greater site fidelity than in other locations and therefore, these animals seem to exhibit considerable behavioural plasticity. Thus it is likely that the complex movements and migrations of these animals could lead to fine-scale distributions, habitat preferences or segregations that have not been detected by trawl surveys or other large-scale studies.

We hypothesised that mechanisms for reducing competition for resources, such as those studied extensively in terrestrial ecosystems (e.g. Feinsinger 1976, Martin 1998, Brosius \& Higley 2013) would also be found in benthic marine ecosystems. Consequently, it was expected that some form of fine-scale segregation would be identified in a group of congeneric and morphologically similar species living in apparent close coexistence, such as the four species of skate studied here. One of the most obvious strategies to reduce competition that these skates might exhibit is differential habitat occupancy. By occupying different habitats animals have access to separate resources and can avoid contact with potential competitors.

Using a range of analysis methods core depth occupancy ranges were identified for all species. The preferred ranges in depth occupancy were found to segregate the 4 species into two pairs; $R$. clavata and $R$. microocellata occupied shallower waters while $R$. brachyura and $R$. montagui occupied deeper water throughout the year. The persistent and significant differences in depths occupied suggest 


\section{Habitat partitioning in marine predators}

preferences for specific depths by each species pair. This apparent segregation was supported by all the analyses performed and in all cases the differences were found to be clear and unambiguous.

Depth ranges for these species in the literature are typically very broad, reflecting the range of depths in which the animals have been found rather than depth preferences, however, there is broad agreement with our findings. For example, $R$. microocellata is reported as an inshore species rarely found at depths $>100 \mathrm{~m}$ (Ellis et al. 2005a) and here is shown to have a depth range of $10-30 \mathrm{~m}$ and a mean depth of $17 \mathrm{~m}$. R. clavata is considered to be most abundant in $10-60 \mathrm{~m}$ (Wheeler 1969) which agrees well with the range found here of $14-24 \mathrm{~m}$. Both $R$. brachyura and $R$. montagui are considered to occur more deeply, with maximum depths of 150 and $283 \mathrm{~m}$ respectively in the north east Atlantic (Ellis et al. 2005a), which although considerably deeper than the 45 and $42 \mathrm{~m}$ maximum depths observed here, still supports these species as occurring in deeper water than the two other species.

It is particularly interesting that such clear segregation in depth preferences was identified in the present study because there are good reasons why it might not have been possible to detect depth segregation between these species. For example, if depth segregation was driven by competitive exclusion then, given recent population declines in most of these species including in the region where they were tracked (Genner et al. 2010), it is possible that current population densities are too low for sufficient inter-species competition. Under such conditions interactions between individuals may be too rare to trigger avoidance behaviour and consequently segregation might not be evident (Prenda et al. 1997). Alternatively, if partitioning was driven by physical habitat (i.e. substrate preference) then depth preferences would reflect the geographic distribution of preferred habitats (e.g. mud, sand or gravel). Given that the study area is a complex mosaic of seabed physical habitats with heterogeneous spatial distribution (see Supporting Information) segregation by depth would not then be evident in the depth time series. Further, spatially complex habitats have been shown to support the coexistence of competitive species by allowing fine-scale spatial segregation (Boeye et al. 2014), consequently allowing shared occupation of similar depth ranges. Consequently, the segregation by depth observed here may more likely represent inherent species preferences.

Further evidence to support an inherent preference as the driver of segregation is that, in the sample of animals used in this study, there was no correlation found between either the weight or the length and the maximum recorded depth, as would be expected if size were a factor in the observed depths (weight, $R^{2}=0.001, p=0.72$; length $R^{2}=0.005, \mathrm{p}=0.52$; SigmaPlot linear regression (Systat Software, San Jose, CA); see Supplementary Information, Figures S7-S8). There is therefore no simple relationship between size and depth with perhaps larger animals being deeper and smaller animals being shallower. It seems likely, therefore, that the depth segregation observed here reflects actual preferred depth ranges in these species. The weekly mean temperature data also provides evidence for 


\section{Habitat partitioning in marine predators}

the segregation being driven by depth preference (Figure 5) where the mean seasonal temperature range $\left(7.25^{\circ} \mathrm{C}\right)$ is significantly greater than differences between the species (mean $1.97{ }^{\circ} \mathrm{C}$; One sample t-test, $p<0.001$ ), indicating that temperature is not a driver for the observed depth preferences. It might be expected that a temperature difference would result simply from the different depths the species occupy, however the study area comprises well mixed coastal waters which do not exhibit the more general marked reduction of temperature with depth observed in other locations, such as well stratified pelagic environments (Pingree \& Griffiths 1978). The thermal mixing of the waters occupied by the skates tracked in this study is further illustrated in Figure S3 (Supplementary Information) which shows mean temperatures computed from all individuals at a range of depths throughout the year and indicates no clear relationship between depth and temperature. For these animals, therefore, temperature would seem to be neither a driver nor a consequence of habitat preference.

The analysis of overlap coefficients again confirms the segregation into two pairs and reveals seasonal changes in the extent of shared vertical occupancy. These changes suggest seasonal movements, for example the degree of overlap between $R$. brachyura and both $R$. clavata and $R$. microocellata diminishes considerably in the autumn, whereas overlap between $R$. montagui and both $R$. clavata and $R$. microocellata is consistently low. These observations suggest that $R$. brachyura is moving offshore during the latter part of the year, whereas both $R$. clavata and $R$. microocellata remain inshore. The continued low level of overlap between $R$. montagui and both $R$. clavata and $R$. microocellata suggests that $R$. montagui is residing in deeper water throughout the year.

An interesting finding is that the species composition of each of the two pairs into which the species in this study are found to segregate represent complementary species within each pair. Firstly, while previous work has identified Raja spp. as generalist feeders, with considerable overlap in prey identified from stomach content analyses (Ellis et al. 1996, Farias et al. 2006), there are significant differences in the most important prey items for each species (Pinnegar 2014). For example, $R$. brachyura and $R$. microocellata have a similar dietary preference, with a slightly greater proportion of teleost prey (54\% and 56\% of the diet respectively) while $R$. clavata and $R$. montagui are similar in having considerably more crustaceans ( $79 \%$ and $81 \%$ of the diet respectively) (Ellis et al. 1996, Šantić et al. 2012, Pinnegar 2014). One species from each pair therefore has a greater preference for crustaceans in the diet (R. clavata and R. montagui), rather than fish. This represents further fine-scale segregation of resources beyond the occupancy of different depths initially explored here. The presence of species with differing diets at the two depths is further strong evidence that the segregation by depth is driven perhaps more by inherent depth preferences as otherwise it might be expected that patterns of segregation would more closely match expected occupancy patterns of prey items. Secondly, each of the pairs contains a larger bodied species ( $R$. brachyura and $R$. clavata have 


\section{Habitat partitioning in marine predators}

maximum recorded lengths of 1200 and $1050 \mathrm{~mm}$ respectively compared to $R$. microocellata and $R$. montagui with maximum lengths of 910 and $800 \mathrm{~mm}$ ). Therefore, while the animals tracked in this study showed no clear relationship between size and depth, the maximum size differences between species might play a role in finer-scale resource partitioning.

How the observed pattern of habitat preference observed here was formed cannot be determined from this study and many different processes might be involved (Wisheu 1998). It is not known for example whether the observed niches represent fundamental preferences or are the result of competitive interactions. Microhabitat characteristics for the study area are poorly understood at present, except for temperature, which has been shown to vary little. Consequently there are at present no clear environmental drivers for the segregation. Further research into depth and habitat preferences of the other sympatric benthic mesopredators common in the region (e.g. plaice, Pleuronectes platessa, turbot, Psetta maxima, or catsharks Scyliorhinus canicula) is required to build a more complete picture of how the assemblage is structured and may have formed.

The current study relies on the depth record and cannot therefore provide the geographic location of the animals. It is possible that there is further geographic separation, or coastal migration that was not possible to detect by this analysis in the present study. While the location of the animals is not known, the core depth preferences can be used with local bathymetry to infer likely spatial extents. Figure 8 shows spatial extents determined using the core mean depth \pm 1 standard deviation. It is clear from these maps that the core depth preferences result in very different spatial extents and likely geographic segregation. Combining these predicted ranges with the boundaries of known or proposed Marine Protected Areas (MPAs) or Marine Conservation Zones (MCZs) might help to give some indication of the extent to which these areas might offer protection from pressures such as fishing with mobile gear and how the different ranges might affect interactions with fisheries.

In summary, while depth preferences indicate an interesting segregation into two pairs of species, with further separation by diet and size, the context of the segregation within the wider species assemblage cannot be understood without similar investigations into the other species common to the area. Studies into depth and habitat preferences of teleosts, such as flatfish (plaice Pleuronectes platessa, turbot Psetta maxima, common sole Solea solea, L.) or other demersal elasmobranchs (Scyliorhinus canicula) are needed to fully understand the patterns of habitat preference reported here. 

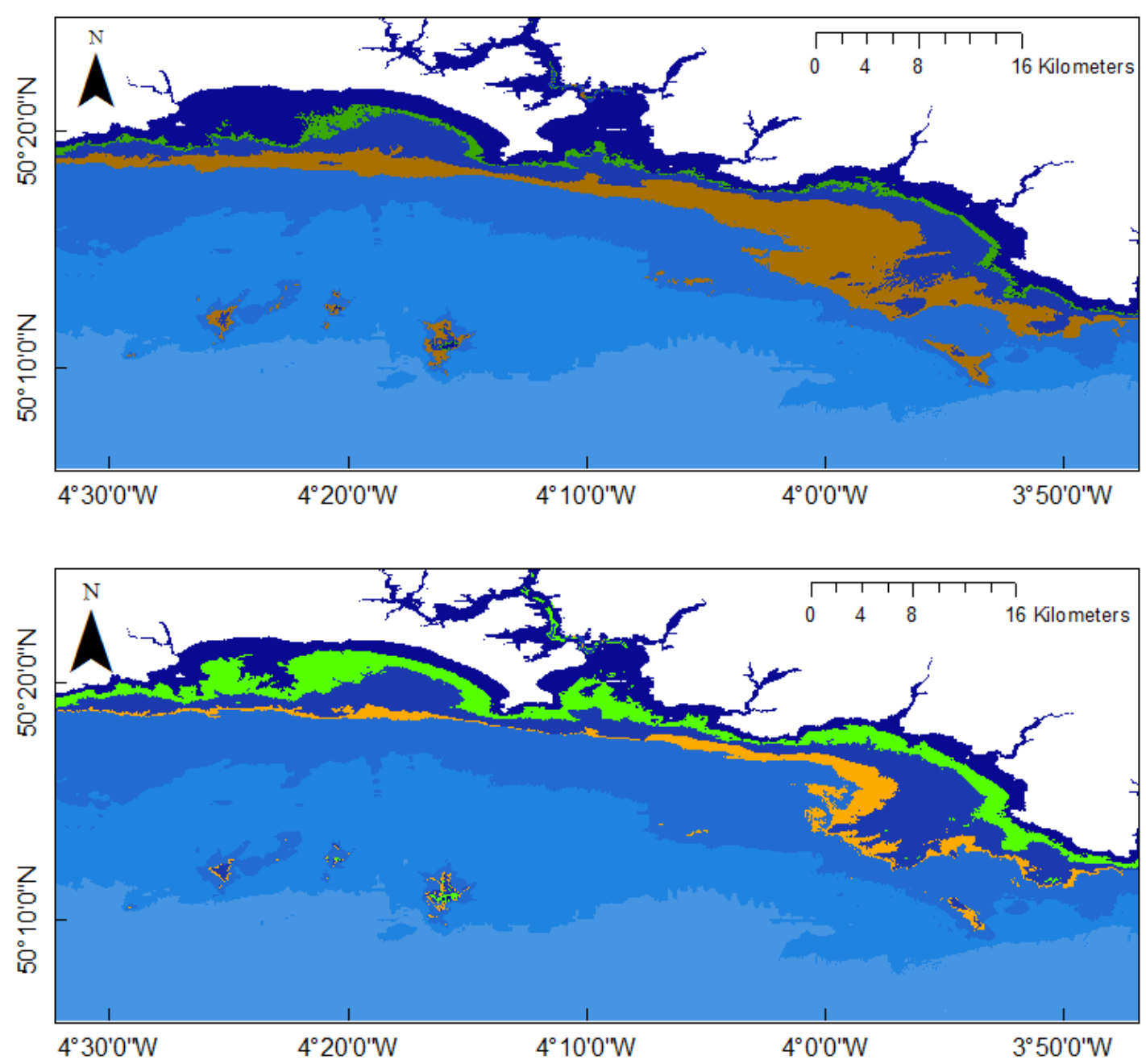

Figure 8: Spatial extents determined from core depth preferences

Top $R$. clavata dark green; $R$. brachyura brown; bottom $R$. microocellata light green, $R$. montagui orange. Differences in core depth preferences result in clearly segregated core spatial extents, given the local bathymetry.

\section{Acknowledgements}

We thank M. McHugh and S. Cotterell for tagging assistance, B. Seeley for help assembling the habitat data, and the captains and crew of RV MBA Sepia and RV Plymouth Quest for provision of animals. Data analysis was supported by the UK Natural Environment Research Council (NERC) Oceans 2025 Strategic Research Programme through an award to D.W.S., and a Marine Biological Association Senior Research Fellowship to D.W.S. S.J.S was supported by a University of Southampton SPITFIRE Doctoral Training Partnership Ph.D. studentship, funded jointly by the Natural Environmental Research Council [Grant number NE/L002531/1] and the Marine Biological Association of the UK (MBA). We also thank all the fishers who returned tags and three anonymous referees for helpful comments which improved the manuscript. 


\section{References}

Bates D, Maechler M, Bolker B, Walker S (2015) Fitting Linear Mixed-Effects Models Using lme4. Journal of Statistical Software 67:1-48

Bizzarro JJ, Broms KM, Logsdon MG, Ebert DA, Yoklavich MM, Kuhnz LA, Summers AP (2014) Spatial Segregation in Eastern North Pacific Skate Assemblages. PLoS One 9

Block BA, Jonsen ID, Jorgensen SJ, Winship AJ, Shaffer SA, Bograd SJ, Hazen EL, Foley DG, Breed GA, Harrison AL, Ganong JE, Swithenbank A, Castleton M, Dewar H, Mate BR, Shillinger GL, Schaefer KM, Benson SR, Weise MJ, Henry RW, Costa DP (2011) Tracking apex marine predator movements in a dynamic ocean. Nature 475:86-90

Boeye J, Kubisch A, Bonte D (2014) Habitat structure mediates spatial segregation and therefore coexistence. Landscape Ecol 29:593-604

Bolle LJ, Hunter E, Rijnsdorp AD, Pastoors MA, Metcalfe JD, Reynolds JD (2005) Do tagging experiments tell the truth? Using electronic tags to evaluate conventional tagging data. ICES J Mar Sci 62:236-246

Botsford LW, Castilla JC, Peterson CH (1997) The management of fisheries and marine ecosystems. Science 277:509-515

Brander K (1981) Disappearance of common skate Raja batis from irish sea. Nature 290:48-49

Brosius TR, Higley LG (2013) Behavioral niche partitioning in a sympatric tiger beetle assemblage and implications for the endangered Salt Creek tiger beetle. PeerJ 1:e169

Cartamil DP, Vaudo JJ, Lowe CG, Wetherbee BM, Holland KN (2003) Diel movement patterns of the Hawaiian stingray, Dasyatis lata: implications for ecological interactions between sympatric elasmobranch species. Mar Biol 142:841-847

Casey JM, Myers RA (1998) Near extinction of a large, widely distributed fish. Science 281:690-692

Ceccarelli DM, Frisch AJ, Graham NAJ, Ayling AM, Beger M (2014) Habitat partitioning and vulnerability of sharks in the Great Barrier Reef Marine Park. Rev Fish Biol Fish 24:169-197

Chevolot M, Ellis JR, Hoarau G, Rijnsdorp AD, Stain WT, Olsen JL (2006a) Population structure of the thornback ray (Raja clavata L.) in British waters. J Sea Res 56:305-316

Chevolot M, Hoarau G, Rijnsdorp AD, Stam WT, Olsen JL (2006b) Phylogeography and population structure of thornback rays (Raja clavata L., Rajidae). Mol Ecol 15:3693-3705

Compagno LJV, Ebert DA (2007) Southern African skate biodiversity and distribution. Environ Biol Fishes 80:125-145 
Compagno LJV, Ebert DA, Cowley PD (1991) Distribution of offshore demersal cartilaginous fish (class Chondrichthyes) off the west-coast of southern Africa, with notes on their systematics. South African Journal of Marine Science-Suid-Afrikaanse Tydskrif Vir Seewetenskap 11:43139

Dellinger RL, Wood PB, Keyser PD, Seidel G (2007) Habitat partitioning of four sympatric thrush species at three spatial scales on a managed forest in west virginia. Auk 124:1425-1438

Dulvy NK, Fowler SL, Musick JA, Cavanagh RD, Kyne PM, Harrison LR, Carlson JK, Davidson LNK, Fordham SV, Francis MP, Pollock CM, Simpfendorfer CA, Burgess GH, Carpenter KE, Compagno LJV, Ebert DA, Gibson C, Heupel MR, Livingstone SR, Sanciangco JC, Stevens JD, Valenti S, White WT (2014) Extinction risk and conservation of the world's sharks and rays. Elife 3

Dulvy NK, Metcalfe JD, Glanville J, Pawson MG, Reynolds JD (2000) Fishery stability, local extinctions, and shifts in community structure in skates. Conserv Biol 14:283-293

Ebert DA, Compagno LJV (2007) Biodiversity and systematics of skates (Chondrichthyes : Rajiformes : Rajoidei). Environ Biol Fishes 80:111-124

Eggleston DB, Hermkind WE, Hines AH (2013) Behavioral Ecology of Mobile Animals: Insights from In Situ Observations. Smithson Contrib Mar Sci:99-114

Ellis J, Dulvy NK, Jennings S, Parker-Humphreys M, Rogers SI (2005a) Assessing the status of demersal elasmobranchs in UK waters: a review. J Mar Biol Assoc UK 85:1025-1047

Ellis JR, Cruz-Martinez A, Rackham BD, Rogers SI (2005b) The distribution of chondrichthyan fishes around the British Isles and implications for conservation. J Northwest Atl Fish Sci $35: 195-213$

Ellis JR, Morel G, Burt G, Bossy S (2011) Preliminary observations on the life history and movements of skates (Rajidae) around the Island of Jersey, western English Channel. J Mar Biol Assoc UK 91:1185-1192

Ellis JR, Pawson MG, Shackley SE (1996) The Comparative Feeding Ecology of Six Species of Shark and Four Species of Ray (Elasmobranchii) In The North-East Atlantic. J Mar Biol Assoc UK 76:89-106

Espinoza M, Munroe SEM, Clarke TM, Fisk AT, Wehrtmann IS (2015) Feeding ecology of common demersal elasmobranch species in the Pacific coast of Costa Rica inferred from stable isotope and stomach content analyses. J Exp Mar Biol Ecol 470:12-25 
Farias I, Figueiredo I, Moura T, Gordo LS, Neves A, Serra-Pereira B (2006) Diet comparison of four ray species (Raja clavata, Raja brachyura, Raja montagui and Leucoraja naevus) caught along the Portuguese continental shelf. Aquat Living Resour 19:105-114

Feinsinger P (1976) Organization of a Tropical Guild of Nectarivorous Birds. Ecol Monogr 46:257291

Field IC, Meekan MG, Buckworth RC, Bradshaw CJA (2009) Susceptibility of sharks, rays and chimaeras to global extinction. In: Sims DW (ed) Advances in Marine Biology, Vol 56, Book 56

Frisk MG, Jordaan A, Miller TJ (2014) Moving beyond the current paradigm in marine population connectivity: are adults the missing link? Fish Fish 15:242-254

Genner MJ, Sims DW, Southward AJ, Budd GC, Masterson P, McHugh M, Rendle P, Southall EJ, Wearmouth VJ, Hawkins SJ (2010) Body size-dependent responses of a marine fish assemblage to climate change and fishing over a century-long scale. Global Change Biol $16: 517-527$

Gotelli NJ, Ellison AM (2013) EcoSimR 1.00. http://www.uvm.edu/ ngotelli/EcoSim/EcoSim.html

Gouraguine A, Hidalgo M, Moranta J, Bailey DM, Ordines F, Guijarro B, Valls M, Barbera C, De Mesa A (2011) Elasmobranch spatial segregation in the western Mediterranean. Sci Mar 75:653-664

Hardin G (1960) The Competitive Exclusion Principle. Science 131:1292-1297

Hayward MW, Kerley GIH (2008) Prey preferences and dietary overlap amongst Africa's large predators. S Afr J Wildl Res 38:93-108

Hobson VJ, Righton D, Metcalfe JD, Hays GC (2007) Vertical movements of North Sea cod. Marine Ecology-Progress Series 347:101-110

Horn HS (1966) Measurements of 'overlap' in comparative ecological studies. Am Nat 100:419:424

Humphries NE, Queiroz N, Dyer JRM, Pade NG, Musyl MK, Schaefer KM, Fuller DW, Brunnschweiler JM, Doyle TK, Houghton JDR, Hays GC, Jones CS, Noble LR, Wearmouth VJ, Southall EJ, Sims DW (2010) Environmental context explains Lévy and Brownian movement patterns of marine predators. Nature 465:1066-1069

Hunter E, Berry F, Buckley AA, Stewart C, Metcalfe JD (2006) Seasonal migration of thornback rays and implications for closure management. J Appl Ecol 43:710-720

Hunter E, Blickley AA, Stewart C, Metcalf JD (2005a) Repeated seasonal migration by a thornback ray in the southern North Sea. J Mar Biol Assoc UK 85:1199-1200 
Hunter E, Buckley AA, Stewart C, Metcalfe JD (2005b) Migratory behaviour of the thornback ray Raja clavata, in the southern North Sea. J Mar Biol Assoc UK 85:1095-1105

Hussey NE, Kessel ST, Aarestrup K, Cooke SJ, Cowley PD, Fisk AT, Harcourt RG, Holland KN, Iverson SJ, Kocik JF, Flemming JEM, Whoriskey FG (2015a) Aquatic animal telemetry: A panoramic window into the underwater world. Science 348:1221-+

Hussey NE, MacNeil MA, Siple MC, Popp BN, Dudley SFJ, Fisk AT (2015b) Expanded trophic complexity among large sharks. Food Webs 4:1-7

Kaiser MJ (2005) Are marine protected areas a red herring or fisheries panacea? Can J Fish Aquat Sci 62:1194-1199

Legare B, Kneebone J, DeAngelis B, Skomal G (2015) The spatiotemporal dynamics of habitat use by blacktip (Carcharhinus limbatus) and lemon (Negaprion brevirostris) sharks in nurseries of St. John, United States Virgin Islands. Mar Biol 162:699-716

Lopez-Lopez L, Preciado I, Velasco F, Olaso I, Gutierrez-Zabala JL (2011) Resource partitioning amongst five coexisting species of gurnards (Scorpaeniforme: Triglidae): Role of trophic and habitat segregation. J Sea Res 66:58-68

Mackas DL, Sefton H, Miller CB, Raich A (1993) Vertical habitat partitioning by large calanoid copepods in the oceanic sub-arctic pacific during spring. Prog Oceanogr 32:259-294

Malavasi S, Franco A, Riccato F, Valerio C, Torricelli P, Franzoi P (2007) Habitat selection and spatial segregation in three pipefish species. Estuar Coast Shelf Sci 75:143-150

Maravelias CD, Tserpes G, Pantazi M, Peristeraki P (2012) Habitat Selection and Temporal Abundance Fluctuations of Demersal Cartilaginous Species in the Aegean Sea (Eastern Mediterranean). PLoS One 7

Martin CS, Vaz S, Ellis JR, Lauria V, Coppin F, Carpentier A (2012) Modelled distributions of ten demersal elasmobranchs of the eastern English Channel in relation to the environment. J Exp Mar Biol Ecol 418:91-103

Martin TE (1998) Are microhabitat preferences of coexisting species under selection and adaptive? Ecology 79:656-670

McCauley DJ, Pinsky ML, Palumbi SR, Estes JA, Joyce FH, Warner RR (2015) Marine defaunation: animal loss in the global ocean. Science (New York, NY) 347:1255641-1255641

McEachran JD, Dunn KA (1998) Phylogenetic analysis of skates, a morphologically conservative clade of elasmobranchs (Chondrichthyes : Rajidae). Copeia:271-290 
Owen-Smith N, Mills MGL (2008) Predator-prey size relationships in an African large-mammal food web. J Anim Ecol 77:173-183

Papastamatiou YP, Wetherbee BM, Lowe CG, Crow GL (2006) Distribution and diet of four species of carcharhinid shark in the Hawaiian Islands: Evidence for resource partitioning and competitive exclusion. Mar Ecol Prog Ser 320:239-251

Pingree RD, Griffiths DK (1978) Tidal fronts on the shelf seas around the British Isles. Journal of Geophysical Research: Oceans 83:4615-4622

Pinnegar JK (2014) DAPSTOM - An Integrated Database \& Portal for Fish Stomach Records. In: Centre for Environment FAS, Lowestoft, UK. (ed)

Platell ME, Potter IC, Clarke KR (1998) Resource partitioning by four species of elasmobranchs (Batoidea : Urolophidae) in coastal waters of temperate Australia. Mar Biol 131:719-734

Prenda J, Armitage PD, Grayston A (1997) Habitat use by the fish assemblages of two chalk streams. J Fish Biol 51:64-79

Queiroz N, Humphries NE, Mucientes G, Hammerschlag N, Lima FP, Scales KL, Miller PI, Sousa LL, Seabra R, Sims DW (2016) Ocean-wide tracking of pelagic sharks reveals extent of overlap with longline fishing hotspots. Proceedings of the National Academy of Sciences 113:1582-1587

R Development Core Team (2015) R: A Language and Environment for Statistical Computing. R Foundation for Statistical Computing, Vienna, Austria.

Rijnsdorp AD, Buys AM, Storbeck F, Visser EG (1998) Micro-scale distribution of beam trawl effort in the southern North Sea between 1993 and 1996 in relation to the trawling frequency of the sea bed and the impact on benthic organisms. ICES J Mar Sci 55:403-419

Šantić M, Rađa B, Pallaoro A (2012) Diet and feeding strategy of thornback ray Raja clavata. J Fish Biol 81:1070-1084

Serra-Pereira B, Erzini K, Maia C, Figueiredo I (2014) Identification of Potential Essential Fish Habitats for Skates Based on Fishers' Knowledge. Environ Manage 53:985-998

Sims DW, Southall EJ, Humphries NE, Hays GC, Bradshaw CJA, Pitchford JW, James A, Ahmed MZ, Brierley AS, Hindell MA, Morritt D, Musyl MK, Righton D, Shepard ELC, Wearmouth VJ, Wilson RP, Witt MJ, Metcalfe JD (2008) Scaling laws of marine predator search behaviour. Nature 451:1098-1102

Speed CW, Field IC, Meekan MG, Bradshaw CJA (2010) Complexities of coastal shark movements and their implications for management. Mar Ecol Prog Ser 408:275-U305 


\section{Habitat partitioning in marine predators}

Speed CW, Meekan MG, Field IC, McMahon CR, Abrantes K, Bradshaw CJA (2012) Trophic ecology of reef sharks determined using stable isotopes and telemetry. Coral Reefs 31:357367

Speed CW, Meekan MG, Field IC, McMahon CR, Stevens JD, McGregor F, Huveneers C, Berger Y, Bradshaw CJA (2011) Spatial and temporal movement patterns of a multi-species coastal reef shark aggregation. Mar Ecol Prog Ser 429:261-U618

Thurstan RH, Brockington S, Roberts CM (2010) The effects of 118 years of industrial fishing on UK bottom trawl fisheries. Nature Communications 1-15

Valls M, Quetglas A, Ordines F, Moranta J (2011) Feeding ecology of demersal elasmobranchs from the shelf and slope off the Balearic Sea (western Mediterranean). Sci Mar 75:633-639

van der Molen J, Rogers SI, Ellis JR, Fox CJ, McCloghrie P (2007) Dispersal patterns of the eggs and larvae of spring-spawning fish in the Irish Sea, UK. J Sea Res 58:313-330

Vitt LJ, Zani PA (1996) Organization of a taxonomically diverse lizard assemblage in Amazonian Ecuador. Can J Zool-Rev Can Zool 74:1313-1335

Wearmouth VJ, Sims DW (2009) Movement and behaviour patterns of the critically endangered common skate Dipturus batis revealed by electronic tagging. J Exp Mar Biol Ecol 380:77-87

Wheeler A (1969) The Fishes of the British Isles and North-West Europe. Macmillan, London

Winter B (2013) Linear models and linear mixed effects models in R with linguistic applications. ArXiv 1308.5499

Wisheu IC (1998) How organisms partition habitats: different types of community organization can produce identical patterns. Oikos 83:246-258

Worm B, Branch TA (2012) The future of fish. Trends Ecol Evol 27:594-599 